\title{
MANAGEMENT OF THE DEAD IN DISASTERS: KNOWLEDGE, ATTITUDES AND SELF- REPORTED PRACTICES AMONGS A GROUP OF ARMY SOLDIERS IN SRI LANKA
}

\section{Chaminda UGG1 \& Warushahennadi J2}

DOI :

http://doi.org/10.4038/sljfms l.v11i 2.7825

Corresponding Author
Chaminda UGG
1 Department of Health
Services Southern Province,
Galle, Sri Lanka
gihanchaminda@gmail.com
iD https:// orcid.org /0000-
0001-6068-4879

2 Department of Forensic Medicine, Faculty of Medicine, University of Ruhuna, Sri Lanka

Key Words

Army soldiers; dead body management; disasters; Sri Lanka

Article History

Received: 10.10.2019

Received in revised form: 08.07.2020

Accepted: 28.07.2020

Available online: 21.2.2020

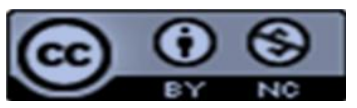

This article is licensed under the terms of the Creative Commons Attribution-Non Commercial 4.0 International License.

e-ISSN: 2465-6089

\begin{abstract}
Introduction:

Improper management of the dead in disasters can hinder the identification, leads to loss of important forensic evidence and affects the dignity of the dead. Army soldiers play a vital role in dead body management in disasters.
\end{abstract}

Objective: To describe the knowledge, attitudes and selfreported practices on management of the dead in disasters among a group of army soldiers in Galle district, Sri Lanka.

Materials and Methods: This descriptive cross-sectional study was conducted using a selfadministered questionnaire. Based on the percentage of correct responses, participants were classified into three groups denoting their overall knowledge using predetermined cut-off values $(>70 \%$ "good", 50-70\% - "moderate", <50\% - "poor" level of knowledge).

Results: The study population was 188 army soldiers $(n=188)$. A majority $(61.2 \%, n=115)$ had a moderate level and $32.4 \% \quad(n=61)$ had a good level of overall knowledge. Knowledge regarding wearing face masks by dead body recovery teams was poor in $92 \%$, while knowledge in spraying disinfectants to dead bodies was poor in $69.1 \%$.
Respectively $21.8 \%$ and $52.1 \%$ believed that funeral rites are not important and dead bodies of foreign nationals should be treated better than locals. A majority (59\%) had reported that they used gloves and boots in dead body recovery process.

Conclusions: Even though a majority had either moderate or good level of overall knowledge, deficiencies of knowledge in certain aspects were evident. A majority had more favourable attitudes and there is a space for improvement in certain practices of dead body management.

\section{INTRODUCTION}

The way that human remains are managed in a disaster situation has a significant impact on the wellbeing of survivors. Improper management of the dead in such situations can lead to loss of valuable forensic evidence, delay the identification of the deceased, and preclude dignified burial. $^{1}$ Thus, inappropriate management of the dead has social, psychological, economic and legal consequences on the survivors, which in turn exacerbates the damage caused by the disaster itself. ${ }^{1}$

Experience from natural disasters such as the 2004 Indian Ocean Tsunami and the 2013 Typhoon Haiyan in the Philippines has shown that the 'first responders' play an important role in managing the dead in disasters. ${ }^{2}$ 
These first responders can do a lot to give the best possible opportunity to investigators to identify the remains of those deceased and clarify the fate of missing people. ${ }^{3}$ In other words, the early work of first responders in a disaster determines the success of much of the work done by medico-legal experts later. Consequently it has a significant influence on the dignity of the deceased and long-term psychological, social, economic and legal impacts on survivors.

Among the stakeholders involved in a disaster response, the army plays a key role. Their role in disaster response has increased in the recent past due to increased incidence and magnitude of natural disasters and increased interest of military institutions in disaster response. ${ }^{4}$ In the Sri Lankan setting army soldiers play a vital role in the process of dead body management in disasters. They act as either responsible persons or supporting persons in almost all activities in dead body management in disasters. ${ }^{1}$ The importance of their role was evident during recovery of human remains in recent disaster situations in the country, such as, the collapse of the garbage dump at Meethotamulla, the landslides at Meeriyabedda and Aranayake.

The objective of this study was to assess the level of knowledge of management of the dead in disasters among army soldiers who are first responders in disasters.

\section{MATERIALS AND METHODS}

This descriptive cross-sectional study was carried out in two selected army camps in the Galle district, Sri Lanka in 2017. The study population included all army soldiers working in the two army camps during the days of data collection. Informed consent was obtained prior to the data collection. Authority was obtained from the Ministry of Defence, Sri Lanka and the respective officials of the Sri Lanka Army. Ethical approval was granted by the Ethics Review Committee of the National Hospital of Sri Lanka. Since data was collected from the entire population, sample size calculation and sampling technique were not applicable.

The data collection instrument was a selfadministered questionnaire in which the contents were in accordance with the objectives of the study. The questionnaire was pre-tested in a small sample of eight army soldiers in Colombo who volunteered to participate in the pre-test. Information for the participants explaining the purpose of the study, ensuring anonymity and confidentiality was included at the beginning of each questionnaire. The face validity of the questionnaire was done and initially it was prepared in English. Then it was translated into Sinhala and Tamil which are the national languages of Sri Lanka. The questionnaire consisted of close ended type questions with four sections. The first section consisted of basic socio-demographic data of the participants. The second section consisted of thirty-three true /false type questions regarding the knowledge on management of the dead in disasters. Attitudes on management of dead in disasters were included in the third section. In the fourth section questions on self-reported practices during management of the dead in disasters were asked.

The army camps were visited by the principal investigator at a pre-arranged time. The questionnaires were administered while the soldiers were physically present in camps and they were requested not to communicate with each other during answering.

Statistical analysis of data was performed using the statistical package for social science (SPSS), version 21. Knowledge on management of the dead in disasters was assessed by scoring the thirty-three items of the second section of the questionnaire. Each correct response was awarded one mark. Thus, the total score ranged from zero to 33 which was converted into a percentage. 
A score of $>70 \%$ was categorized as having a "good" level, a score of $<50 \%$ was categorized as having a "poor" level, and a score of $50-70 \%$ was considered as having a "moderate" level of knowledge on management of the dead in disasters. Socio demographic characteristics, individual items assessing the knowledge, attitudes and practices on dead body management in disasters were described using frequency distributions. Overall level of knowledge was cross analyzed with service duration and highest educational level to identify possible associations using chi square test of independence. A probability value of less than 0.05 was considered as significant.

\section{RESULTS}

The study sample consisted of 188 male army soldiers. A majority $(51.6 \%, \mathrm{n}=97)$ were in 31 40 years of age whereas $31.4 \%(n=59)$ of the study sample was 30 years old or below. $43.6 \%$ $(n=82)$ had passed the General Certificate of Education Ordinary Level (GCE O/L) examination. Majority $(64.9 \%, n=122)$ of the participants had a service of 10 years or more in Army.

The participants were asked different aspects of the management of the dead in disasters. Out of the total, $67.6 \%$ have answered correctly to the false statement "Dead body recovery is the most urgent task in a disaster". While 81.9\% knew that establishment of a scene management team is necessary, $87.2 \%$ and $92 \%$ respectively were aware that a body receiving point has to be determined and a body recovery register should be maintained before dispatching the bodies from the scene.

The participants were questioned regarding numbering of the bodies and $93.6 \%$ knew that a unique reference number should be given to each body and $87.2 \%$ said that the number tags should be attached to the wrist or ankle of a complete body.

Majority (92\%) agreed that the bodies should be released after confirming the identification and $51.6 \%$ responded correctly to the false statements that every attempt shoud be made to identify the bodies and all attached personnel belongings should be removed $(54.8 \%)$ at the scene itself. Only $36.2 \%$ of the participants responded correctly to the false statement that obtaining a single photograph of a body is adequate.

Regarding fragmented bodies, $45.7 \%$ stated that every body part should be considered as a separate individual and $52.7 \%$ thought that all fragmented pieces in a particular area could be collected into a single container. While $66.5 \%$ have responded correctly as false to the statement that the recovery team should attempt to match body parts at the scene, $52.1 \%$ have responded correctly to the false statement that the personal belongings separated from the body belongs to the closest body.

Majority (77.1\%) stated correctly that the bodies should be placed in separate body bags with personal belongings, sealed (74.5\%), and that plastic sheets, bed sheets or other available material may be used as an alternative, if body bags were not available (86.7\%). Only $34 \%$ knew that ambulances should not be used to transport the bodies.

Out of the total, $76.6 \%$ were aware that refrigeration of dead bodies between $2{ }^{\circ} \mathrm{C}$ and 4 ${ }^{0} \mathrm{C}$ is the best option for storage of bodies, while $47.3 \%$ were aware that the temporary burial is also a good option, when no other method is available. While $71.8 \%$ knew that laying bodies on top of each other, with an intervening layer of soil in temporal burial is wrong, and only $37.2 \%$ knew that using iced water for storage of bodies is not useful.

$92 \%$ of the participants in the study knew correctly, that handling dead bodies carries only a small risk of infection through contact with blood and faeces. But only a few (8\%) knew that wearing a face mask and spraying disinfectants (30.9\%) to dead bodies is not essential during body recovery. 
Several administrative issues which are commonly faced by the first responders at the scene of mass disasters were included into the questionnaire. Of the participants, $91 \%$ were aware that legal problems that arise to the relatives as a consequence of mismanagement of the dead. However, $52.1 \%$ and $44.7 \%$ have given a correct response to the false statements 'politicians can participate' and 'direct communication with outsiders/media should be done' respectively. Only $51.1 \%$ knew that journalists should not be allowed on the scene immediately after the disaster.

Table 1: Items in the questionnaire for which the participants' knowledge was poor $(n=188)$

\begin{tabular}{|c|c|}
\hline Item & $\begin{array}{l}\text { Percentage of participants } \\
\text { who responded correctly }\end{array}$ \\
\hline $\begin{array}{l}\text { Wearing face masks is essential for teams involved in dead body } \\
\text { recovery (False) }\end{array}$ & 08.0 \\
\hline Spraying disinfectants to dead bodies is essential (False) & 30.9 \\
\hline Ambulences should not be used to transport the dead bodies (True) & 34.0 \\
\hline $\begin{array}{l}\text { Obtaining a single photograph in relation to an individual body is } \\
\text { adequate (False) }\end{array}$ & 36.2 \\
\hline Ice (frozen water) should be used for storage of dead bodies (False) & 37.2 \\
\hline $\begin{array}{l}\text { Direct communication with outsiders/media and revealing } \\
\text { information should be done by all the team members (False) }\end{array}$ & 44.7 \\
\hline $\begin{array}{l}\text { Every body part that is completely separated should be treated as a } \\
\text { separate individual (False) }\end{array}$ & 45.7 \\
\hline $\begin{array}{l}\text { Temporary burial is a good option for immediate storage where no } \\
\text { other method is available (True) }\end{array}$ & 47.3 \\
\hline
\end{tabular}

The majority of the participants $(61.2 \%, \mathrm{n}=115)$ were found to have a "moderate" level of overall knowledge on management of the dead in disasters whereas $32.4 \%(n=61)$ were found to have a "good" level of overall knowledge. Level of education was significantly associated with the overall knowledge on management of the dead in disasters (Chi-square 6.023, $\mathrm{df}=2, \mathrm{p}<.05$ ). There was not enough evidence to suggest a significant association between the service duration in the army with the overall knowledge (Chi-square 1.142, $d f=2, p=.565$ ).

Attitudes of the study population were assessed using ten attitudinal statements (Table 2). 
Table 2: Attitudes on management of the dead in disasters $(n=188)$

\begin{tabular}{|c|c|c|c|}
\hline Statement & Agree & Disagree & $\begin{array}{c}\text { Not } \\
\text { answered }\end{array}$ \\
\hline Dead bodies of children should not be given priority & 10.1 & 89.4 & 0.5 \\
\hline There is no need to respect dead bodies as they are dead. & 12.8 & 86.7 & 0.5 \\
\hline $\begin{array}{l}\text { Identification of dead individuals is not important in } \\
\text { disasters as there are large numbers of casualties. }\end{array}$ & 19.7 & 79.3 & 1.1 \\
\hline Funeral rites are not important. & 21.8 & 76.1 & 1.1 \\
\hline Mistaken identity is not a big issue to be worried. & 23.4 & 75.0 & 1.6 \\
\hline $\begin{array}{l}\text { Pre planning for disasters is a waste of money and time as } \\
\text { disasters are unpredictable. }\end{array}$ & 25.5 & 72.3 & 2.1 \\
\hline $\begin{array}{l}\text { Necessity of members of the affected families to know the } \\
\text { fate of their loved ones should not be a priority. }\end{array}$ & 27.7 & 71.3 & 1.1 \\
\hline Following guidelines is impractical. & 33.0 & 65.4 & 1.6 \\
\hline $\begin{array}{l}\text { Unidentified bodies should be buried in common graves to } \\
\text { save time and money. }\end{array}$ & 48.9 & 50.0 & 1.1 \\
\hline $\begin{array}{l}\text { Management of bodies of foreign nationals should be } \\
\text { treated better than the locals. }\end{array}$ & 52.1 & 47.3 & 0.5 \\
\hline
\end{tabular}

Majority of the participants ( $n=130,69.1 \%$ ) had experience in dead body management as army soldiers. The practices they followed in the management of the dead in disasters as seen in Table 3.

Table 3: Practices in the management of the dead in disasters $(n=130)$

\begin{tabular}{lr}
\hline Practice & Percentage \\
\hline Burial of a large number of dead bodies in a common grave (No) & 35.6 \\
\hline Matching of body parts with incomplete bodies at the disaster scene (No) & 41.5 \\
\hline Establishment of a scene management team immediately after a disaster (Yes) & 44.7 \\
\hline Assigning a unique reference number to each body (Yes) & 51.6 \\
\hline Tagging of each body with a unique reference number (Yes) & 51.6 \\
\hline Sealing of body bags after placing bodies (Yes) & 53.2 \\
\hline Obtaining photographs of the disaster scene and dead bodies (Yes) & 53.7 \\
\hline Placing of each dead body in a separate body bag (Yes) & 54.8 \\
\hline Use of ambulances to transport dead bodies (No) & 58.0 \\
\hline Use of gloves and boots in dead body recovery process (Yes) & 59.0 \\
\hline
\end{tabular}




\section{DISCUSSION}

The level of overall knowledge of study population in the study is satisfactory with the majority (93.6\%) having either moderate or good level of overall knowledge on management of the dead in disasters. Yet considerable gaps in important aspects of dead body management were evident. In particular, knowledge on wearing face masks by personnel involved in dead body recovery, taking photographs, spraying disinfectants to dead bodies and use of ambulances to transport the dead was poor.

Though a majority (92\%) knew that individuals handling dead bodies have a small risk of infections via contact with blood and faeces, only a minority (8\%) knew that wearing face masks is not essential for teams involved in dead body recovery. Facemasks do not filter or provide protection for a considerable period of time and they can slow down some tasks of the users such as moving, storing, and preparing corpses. Moreover, the danger of contamination via respiratory tract is minimal since there is no respiratory function in dead bodies ${ }^{5}$

Guidelines state that the dead bodies should not be transported in ambulances and vehicles used for transportation of consumable items. ${ }^{5}$ In the present study, only $34 \%$ of the participants were aware of it. Assigning a unique reference number to each body or body part is a must ${ }^{1}$ to avoid loss of bodies, to ensure traceability and correct documentation, and to enhance identification of the deceased. ${ }^{2}$ Interestingly a majority (93.6\%) of respondents in the study were aware of it.

Although there was not enough evidence to suggest a significant association between service duration of soldiers with overall knowledge on management of the dead in disasters (Chi-square 1.142, $\mathrm{df}=2, \mathrm{p}=.565$ ), level of education was significantly associated with overall knowledge (Chi-square 6.023, df=2, $\mathrm{p}<.05$ ). In a study conducted on mass fatality preparedness among coroners / medical examiners in United States, conducting training programmes had a significant association with preparedness measures. ${ }^{6}$

This study showed that a majority of participants had more favourable attitudes in many aspects of management of the dead in disasters although there were some negative attitudes to a certain extent. In a study conducted among health care workers, most of the participants had highly positive attitudes towards mass fatality management following disasters. $^{7}$

Usually the bereaved want to see the corpse to say "goodbye" and to conduct ceremonious funerals. ${ }^{8}$ Only $21.8 \%$ of participants in this study believed that funeral rites are not important in management of dead in disasters. Similarly, an Indonesian study stated, "Participants identified that right to mourn and the right to be treated according to one's religion even after death". ${ }^{9}$

A noteworthy finding of this study is the attitude of more than half $(52.1 \%)$ of the study subjects that management of bodies of foreign nationals should be treated better than the locals. Guidelines laid by College of Forensic Pathologists of Sri Lanka clearly state that, "Every victim, foreign or Sri Lankan, would be treated equally". ${ }^{1}$ It is well documented in the field manual for first responders that; "Pressure to prioritize the finding of foreign nationals must not be allowed to distort the priorities of a systematic local approach to identifying all the dead". ${ }^{2}$

Regarding self-reported practices pertaining to management of the dead in disasters, more than half $(54.8 \%, n=103)$ of the study population reported that they have placed each dead body in a separate body bag whereas $51.6 \%(n=97)$ of participants have stated that they have assigned and tagged a Unique Reference Number to each dead body. But according to Perera and Briggs, following the Indian Ocean Tsunami in 2004, tagging of dead bodies with 'permanent identification codes' was not done before disposing them. ${ }^{10}$ 
To our knowledge, this is the first study conducted in Sri Lanka to describe the knowledge, attitudes and practices on management of the dead in disasters among first responders. It could be considered as a major strength of this study and the findings will aid to bridge the gaps in the subject. One limitation of this study is that it was confined to male soldiers. Secondly, as data was collected using a self - administered questionnaire, there's a possibility that participants may have provided socially desirable responses, especially with regard to practices rather than the actual practices that they had engaged. There could be an element of recall bias with regard to practices since the data asked about practices were not confined to the recent past.

Even though a majority of army soldiers had either "moderate" or "good" level of overall knowledge on management of the dead in disasters, deficiencies of knowledge in certain aspects were evident. A majority of participants had more favourable attitudes in many aspects of management of the dead in disasters although there were some negative attitudes to a certain extent. There is a space for improvement in certain practices of dead body management.

This study recommends improving the training opportunities for army soldiers to enhance their knowledge and experience on management of the dead in disasters. More consideration should be given to offer specific instructions on different aspects of dead body management during training programmes.

\section{ETHICAL ISSUES}

The Ethical Review Committee of the National Hospital of Sri Lanka has granted approval for this study.

\section{CONFLICTS OF INTEREST}

There are no conflicts of interest.

\section{ACKNOWLEDGEMENTS}

Authors wish to thank the Ministry of Defence, Sri Lanka for giving the permission to proceed with the research and the Divisional Commander of $58^{\text {th }}$ division, Brigade Commander of 581 Brigade and Commanding Officers of the selected camps of Sri Lanka Army for the support they have given during the data collection. Authors wish to express gratitude to all army soldiers who participated in this study and all the experts who contributed for the translation of the questionnaire.

\section{AUTHOR CONTRIBUTIONS}

UGGC: Conception and design of the work, acquisition, analysis and interpretation of data, drafting the work and critical revision, and final approval; JW: Conception and design of the work, acquisition, analysis and interpretation of data, drafting the work and critical revision, and final approval.

\section{REFERENCES}

1. Weeratna JB, Paranirubasingam $P$, Perera SDC, Hewage SPA, Attygalle U. Management of the Dead in Disasters and Catastrophes. 1st ed. Colombo: College of Forensic Pathologists of Sri Lanka; 2016.

2. Cordner S, Coninx R, Kim H, Van Alphen D, Tidball-Binz M. Management of Dead Bodies after Disasters: A Field Manual for First Responders. 2nd ed. Washington D.C.: Pan American Health Organization; 2016.

3. World Health Organization. Handling dead bodies with dignity when disaster strikes. Available from: http://www.who.int/ hac/techguidance/dead-bodiesmanagement/en/ [Accessed 15th June 2017].

4. Thapa M. Out of Barracks: Civil-Military Relations in Disaster Management; A Case Study of Nepalese Army's Humanitarian Response during 2015 Earthquake in Nepal. Ideas for Peace report by the United Nations University for Peace. Available from: https://www. upeace.org/uploads/file/Ideas01.pdf [Accessed 2nd December 2017]. 
5. Management of dead bodies in disaster situations (Disaster Manuals and Guidelines Series, № 5). Washington, D.C.: Pan American Health Organization; 2004. Available from: https://www.who.int/

hac/techguidance/management_of_dead_bodi es.pdf [Accessed 15th June 2017].

6. Gershon RR, Orr MG, Zhi Q, et al. Mass fatality preparedness among medical examiners/coroners in the United States: a cross-sectional study. BMC Public Health. 2014; 14(1). Available from: https://www.ncbi.nlm.nih.gov/pmc/articles/PM C4320632/pdf/12889_2014_Article_7476.pdf

[Accessed 8th November 2017].
doi:10.1186/1471-2458-14-1275.

7. Rajapaksha N, Fernando DMG, Vallipuranathan $M$. Dead body management following disasters: capacity assessment of district general hospital, Trincomalee. Journal of Kurunegala Clinical Society. 2015; 7 :38-48.
8. Sumathipala A, Siribaddana S, Perera C. Management of dead bodies as a component of psychosocial interventions after the tsunami: A view from Sri Lanka. International Review of Psychiatry. 2006; 18(3):249-257. doi: $10.1080 / 09540260600656100$

9. Bagherzadeh N. Death in Disaster, Actions and Attitudes towards Dead Body Management after Disasters in Yogyakarta. IFHV Working Paper, 2014, 4 (2). Available from: http://www.ruhr-uni-bochum.de/ ifhv/documents/workingpapers/wp4_2.pdf [Accessed 15th June 2017].

10. Perera C, Briggs C. Guidelines for the effective conduct of mass burials following mass disasters: post-Asian Tsunami disaster experience in retrospect. Forensic Science, Medicine, and Pathology. 2008; 4: 1-8. doi:10.1007/s12024-007-0026-1. 